\title{
ACEVEDO MARIN, Rosa Elizabeth. A escrita da história paraense. Belém, NAEA-UFPA, 1998
}

\section{Elaborada por Francinete Cardoso}

O processo de ocupação da Amazônia feito pelos portugueses foi articulado através de diversos projetos que, geralmente, tinham como finalidade a garantia da segurança da posse dessas terras em relação aos interesses estrangeiros. Situando-se como um trabalho sobre a realidade histórica da Amazônia, o texto "Agricultura no delta do rio Amazonas: colonos produtores de alimentos em Macapá no período colonial", da professora Rosa Elizabeth Acevedo Marin, servirá como objeto de análise desta resenha que acima de tudo objetiva discutir um pouco da história colonial da Amazônia, enfatizando o seu processo de ocupação.

Acevedo Marin tem como objetivo principal, no texto aqui analisado, apresentar o processo de instauração e organização de colonos produtores de arroz em Macapá. Verifica como o projeto de rizicultura foi implantado na região e, ao mesmo tempo, aborda as diversas condições econômicas, políticas e sociais experimentadas por esta agricultura em Macapá, que representou muito mais do que uma simples tentativa do cultivo de um produto agrícola em uma região primordial para a garantia do controle de fronteira, nessa área, os estudos, ainda hoje, enfatizam apenas a economia extrativista.

Inicialmente, a autora apresenta a importância do arroz para as sociedades asiáticas, observando que nessas sociedades o arroz é plantado em solos inundáveis e representa a grande fonte de alimentação. A partir dessas colocações, a autora passa a demonstrar que o delta amazônico apresentava todas as possibilidades necessárias para o desenvolvimento da rizicultura, porém a autora coloca o problema histórico do sucesso deste cultivo na região, demonstrando a necessidade de se buscar na história questões às quais não é possível responder, simplesmente, por adaptações naturais da agricultura ao meio determinado para o cultivo, ou seja, às condições fornecidas geograficamente.

O sucesso histórico da plantação de arroz no delta do rio Amazonas servirá como questão central de todo o trabalho da autora. Desta forma, podemos observar que a autora trabalha, como coloca François Furet, a partir de uma história-problema, não se contentando com respostas previamente elaboradas, mas indo às fontes de forma que estas possam ser analisadas para a construção

${ }^{1}$ ACEVEDO MARIN, Rosa Elizabeth. A escrita da história paraense. Be1ém: Universidade Federal do Pará, 1998, p.53-92. 
do conhecimento histórico ${ }^{2}$. A principal questão que a autora observa é que a rizicultura tinha todas as condições físicas necessárias para o seu pleno desenvolvimento, porém, tendo por interesse o estudo da agricultura, a autora deixa perceber que o sucesso desta atividade está diretamente relacionado com a sua constituição no decorrer das relações que envolveram os diversos sujeitos sociais presentes.

Acevedo Marin afirma que o cultivo do arroz apresentava-se como um projeto de ocupação e aproveitamento da região. Observa que, além da defesa militar ocorrida através das construções de fortes e fortalezas, ocorreu também a projeção da estrutura agrária e camponesa, que tinha como finalidade o controle da população da região, como coloca a autora: “...organizar redes e relações de poder sobre os grupos familiares dedicados à agricultura do arroz em Macapá teve como finalidade servir principalmente para a ocupação e controle da região. Consideramos isto realmente interessante do ponto de vista da construção do conhecimento histórico, pois Acevedo Marin consegue, a partir o estudo da implantação de uma colônia agrícola rizicultora, perceber relações de dominação e controle dos sujeitos sociais e da própria fronteira em face dos constantes perigos de invasão estrangeira.

A construção histórica feita pela autora permite-nos dizer que se trata de um trabalho na linha da micro-história, como coloca Carlo Gizburg: "A análise micro-histórica é, portanto, bifronte. Por um lado, movendo-se numa escala reduzida, permite em muitos casos uma reconstituição do vivido impensável noutros tipos de historiografia. Por outro lado, propõe-se indagar as estruturas invisíveis dentro das quais aquele vivido se articula...."

A partir do estudo de um núcleo colonial em Macapá, a autora mostra-nos as relações de dominação não apenas nesta região, mas também as formas de relações que se processaram em diversas áreas da Amazônia brasileira.

Entre os diversos autores e documentos utilizados pela autora, observamos a constante referência ao trabalho do padre João Daniel. Este teria certos posicionamentos sobre as paisagens geográficas e o solo da região que eram favoráveis ao desenvolvimento da plantação.

No trabalho de Acevedo Marin, encontramos a preocupação com a construção de uma história regional, havendo em diversos momentos referências

\footnotetext{
${ }^{2}$ FURET, François. Data história-narrativa à história-problema. In: A oficina da história Lisboa: Gradiva, [s.d], p. 81-98.

${ }^{3}$ GINZBURG, Carlo. A miero-história e outros ensaios. Rio de Janeiro: Difel, 1991, p. 178.
} 
às questões específicas da região, ou seja, a cultura regional que, num primeiro momento, não tinha como hábito o consumo do arroz: a base da alimentação eram os tubérculos. Há também a apresentação de todo o processo de ocupação do delta amazônico, utilizando a autora constantemente as informações fornecidas pelo padre João Daniel.

A plantação de arroz em Macapá fazia parte da formação de um celeiro agrícola na planície fluvial amazônica e tinha como finalidade do "projeto de colonização de Macapá”. O colono, dessa forma, assume dupla função, ou seja, era colono e soldado. Também passa por uma intensa opressão por parte das autoridades do Estado. A vinda de "colonos açorianos" para a colonização de Macapá e Magazão, neste sentido, assume para a autora uma alternativa de controle do espaço e da própria população que ocupava esse espaço em nome do governo português. Acevedo Marin evidencia que as relações entre colonos e instituições coloniais marcam a agricultura camponesa, ou seja, persistem enquanto problemas centrais da agricultura camponesa.

Outra questão abordada por Acevedo Marin é o alto contingente populacional exigido por esse tipo de produção, que é uma agricultura intensiva e que no Maranhão passou por bom desenvolvimento. Baseada nos escritos do padre João Daniel, a autora observa que as terras possuíam todas as condições para o bom desenvolvimento da rizicultura e que os colonos dispunham de condições geográficas favoráveis para uma produção diversificada (policultura), bem como para a criação de gado bovino. Porém, para tornarem-se fornecedores do arroz para a Europa, fazia-se necessário o cultivo de sementes do arroz "manso", bem como o processo de financiamento desse cereal, assim poderiam obter lucros maiores, pois os leitos dos rios Araguaia e Amapari apresentavam áreas de várzea.

A autora observa que a região necessitava ser protegida das ameaças francesas; na condição de fronteira, era necessário que Macapá se tornasse uma área de destaque agrícola, haja vista, que a França perdera, em 1763, a região em litígio para o Brasil.

Observamos neste trabalho o destaque ao duplo projeto, militar e agrícola, na região, que deveria ter como condutores as mesmas pessoas, o que provocou uma espécie de deserção por parte de alguns colonos. A autora deixa em aberto a questão do controle por parte da coroa portuguesa em relação á entrada e saída de colonos da região.

A autora dá também especial destaque para os interesses comerciais do governo português em relação á produção do arroz, que deveria ser feita a partir das exigências do mercado europeu: 
"Os problemas e inovações sobre o descasque do arroz constituem outro aspecto interessante na história agrária. Buscava-se uma variedade menos quebradiça na fase do descasque com auxílio de moinho e de cor branca, para aceitação no mercado europeu".

A autora, a partir de fontes documentais diversas, observa toda a preocupação com o beneficiamento do arroz, além das dificuldades em adquirir as sementes para o plantio. Fora essas questões, não raro o arroz ficava estragado por causa da umidade provocada pela falta de proteção. Outra questão enfatizada é a presença da Companhia de comércio do Grão Pará e Maranhão que exercia um amplo monopólio sobre as atividades econômicas, causando geralmente o endividamento dos colonos e a falta de mão-de-obra para a colheita do arroz.

Conforme Acevedo Marin, o monopólio da Companhia de Comércio sobre as negociações do arroz algumas vezes sofreu certa tentativa de corte no que concerne à venda feita pelos colonos. Estes algumas vezes tentavam vender seus produtos para compradores diretos, o que era amplamente denunciado pela própria Companhia de Comércio, que se sentia prejudicada.

A autora observa a preponderância de uma economia de troca que facilitava o endividamento do agricultor para com a companhia. Esse endividamento, bem como toda uma rede de relações econômicas, em que o comércio de arroz apresentava-se deficitário para o colono, foram fatores decisivos para o fracasso da rizicultura no Pará.

Sabemos que o processo histórico é feito de continuidades e descontinuidades que fornecem sentido às relações historicamente constituídas. Como coloca Philippe Aries, é necessário buscar conhecer e compreender essas continuidades e descontinuidades, bem como as particularidades que caracterizam as diversas sociedades ${ }^{5}$. Consideramos que é este exatamente o trabalho que a professora Rosa Acevedo procura fazer, trabalhando a regionalidade e a existência dos colonos, a que jamais seria percebido em uma história das grandes estruturas. Essa parece ser a grande questão que a história nos coloca, a necessidade de se buscar os homens na sua existência, nas suas relações econômicas e sociais, ou seja, de nada adiantam modelos pré-elaborados se o historiador não consegue chegar ao vivido através da análise das fontes.

\footnotetext{
${ }^{4}$ Ibidem, p. 69.

${ }^{5}$ ARIES, Philippe. Uma nova educação no olhar. In: História e Nova História. Lisboa: Editorial Teorema, 1986, p. 21-31.
} 
Observamos que Acevedo Marin, ao estudar a história da agricultura, faz um amplo trabalho de reconstituição histórica que fornece as particularidades que envolvem as relações econômicas, sociais e políticas que se processaram na região amazônica, um universo de informações preciosas para quem faz história regional, sem cair no amplo esquematismo da história totalizante que nega as particularidades regionais.

No decorrer da leitura do trabalho desta autora, observamos uma colocação feita por Barbára Weistein ${ }^{6}$, que a princípio pode parecer deslocada, porém que assume bastante relevância se considerarmos que a autora citada demonstra a importância do historiador que evita cair nos grandes ciclos econômicos ou ainda na simples teoria da dependência que nega a historicidade da região. Só temos a acrescentar que a grande gama de informações contidas no texto da professora Acevedo Marin por vezes impede que ouçamos de forma mais clara a voz da própria pesquisadora, o que provavelmente tornaria o trabalho de mais fácil compreensão.

\footnotetext{
${ }^{6}$ Em seu trabalho "A borracha na Amazônia: expansão e decadência (1850-1920)", Barbára Weintein critica a história tradicional que estuda as regiões a partir de modelos pré-elaborados que fogem à própria historicidade, no caso, a Amazônia. Embora essa autora trate de uma economia extrativista, encontramos um ponto em comum com o trabalho de Acevedo Marin, que é a preocupação de situar a região em suas particularidades para poder depois compreendê-la num contexto macro. É essa escrita histórica que permite não se fazer história a partir de concepções que apresentam a região como área periférica.
} 